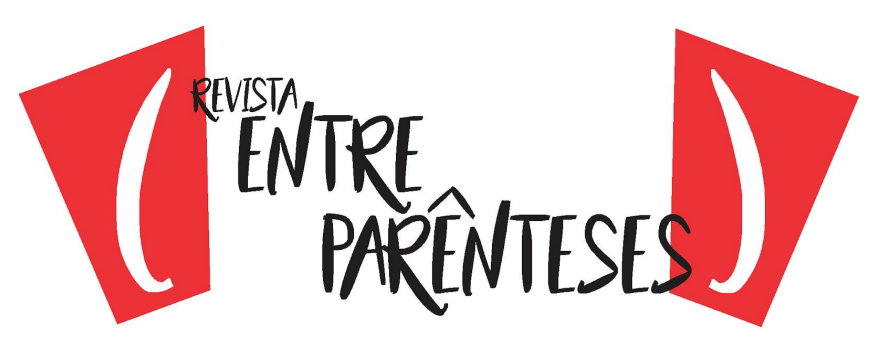

\title{
O EMBATE CULTURAL ENTRE O COLONIZADOR E O COLONIZADO NA AMAZÔNIA BRASILEIRA
}

\author{
Ivanete da Silva Alves \\ Universidade Federal de Minas Gerais \\ (Ivanety_23@hotmail.com ${ }^{1}$ )
}

\begin{abstract}
Resumo: Refletir sobre as interações no espaço cultural entre colonizador e o colonizado na Amazônia brasileira é o intuito deste trabalho, que desenvolveu-se por meio da análise do romance Cinzas do norte (2005), de Milton Hatoum. Escolheu-se essa narrativa porque ela aponta para a problemática da migração na região. Ao longo do período de colonização desse espaço a cultura dos povos nativos foi subjugada em decorrência da postura hegemônica do colonizador. Os conquistadores sempre desejaram impor seus princípios culturais a esses povos. No entanto, observa-se que, embora tenha havido certo sincretismo, as etnias demonstram resistência diante do colonialismo ao manter muito dos seus preceitos.
\end{abstract}

Palavras-chave: Colonizador; colonizado; Amazônia; cultura.

Abstract: Reflecting on the interactions in the cultural space between colonizer and colonized in the Brazilian Amazon is the purpose of this work, which was developed through the analysis of the novel Cinzas do norte (2005) by Milton Hatoum. This narrative was chosen because it points to the issue of migration in the region. Throughout the period of colonization of this space the culture of the native peoples was subjugated as a result of the hegemonic posture of the colonizer. The conquerors have always wished to impose their cultural principles on these peoples. However, it is observed that, although there was a certain syncretism, the ethnic groups demonstrate resistance to the colonialism while maintaining much of their precepts.

Keywords: Colonizer; colonized; Amazônia; culture.

Resumen: Reflexionar sobre las interacciones en el espacio cultural entre colonizador y el colonizado en la Amazonia brasileña es la intención de este trabajo, que se desarrolló por medio del análisis de la novela Cinzas do norte (2005), de Milton Hatoum. Se escogió esa narrativa porque apunta a la problemática de la migración en la región. A lo largo del período de colonización de ese espacio la cultura de los pueblos nativos fue subyugada como consecuencia de la postura hegemónica del colonizador. Los conquistadores siempre desearon imponer sus principios culturales a esos pueblos. Sin embargo, se observa que, aunque ha habido cierto sincretismo, las etnias demuestran resistencia ante el colonialismo al mantener mucho de sus preceptos.

Palabras clave: Colonizador; colonizado; Amazonia; cultura.

\section{Introdução}

\footnotetext{
${ }^{1}$ Possui Graduação em Letras Português pela Universidade Federal do Pará. Mestranda em Estudos Literários. Área de concentração: Teoria da Literatura e Literatura Comparada. Linha de pesquisa: Literatura, História e Memória Cultural na Universidade Federal de Minas Gerais.
} 


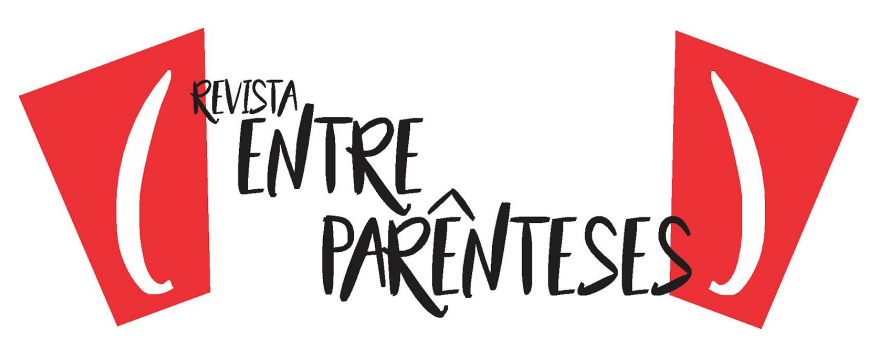

O romance, Cinzas do norte de Milton Hatoum publicado em 2005 narra a trajetória de Raimundo (Mundo), filho de Trajano Mattoso (Jano), de origem portuguesa e uma mestiça, Alícia. Assim, o personagem revela-se um híbrido, resultados das migrações na região. O protagonista vive em atrito com o pai em decorrência de divergências ideológicas. O patriarca evidencia valores eurocêntricos e despreza a cultural nativa.

A narração mostra conflitos individuais, familiares e coletivos. Ela focaliza uma Manaus habitada por diferentes sujeitos, em processo de modernização sob os dogmas de civilização e progresso e permeada por vários problemas de cunho social e político. Nesse ambiente, a maioria das pessoas encontra-se excluída das promessas modernizadoras, como ocorre com os indígenas que perderam seu espaço natural em decorrência da colonização e passaram a viver de modo degradante no espaço urbano.

Desse modo, o texto hatouniano aborda questões relevantes em torno do campo cultural na Amazônia brasileira. Ele põe em pauta os processos migratórios para esse lugar e as ações colonialistas. A narrativa também expõe o desejo do colonizador pelo apagamento da cultura dos povos regionais e a resistência desses indivíduos.

A obra pontua questões contundentes dessa região tão ampla e complexa. Nela, os diversos povos precisam lidar com a diferença do outro. Considerando isso, intenta-se compreender neste trabalho a interação entre a cultura do colonizador e a da população local na Amazônia brasileira. Para isso, será feita uma abordagem sobre os processos migratórios nesse espaço.

\section{Migrações na Amazônia}

A região amazônica, desde o início de sua ocupação pelos europeus foi admirada por "seus recursos imensos reais e imaginários" (GONÇALVES, 2005, p. 25). A vasta floresta sempre foi motivo de desejo. É por isso que Weinstein 


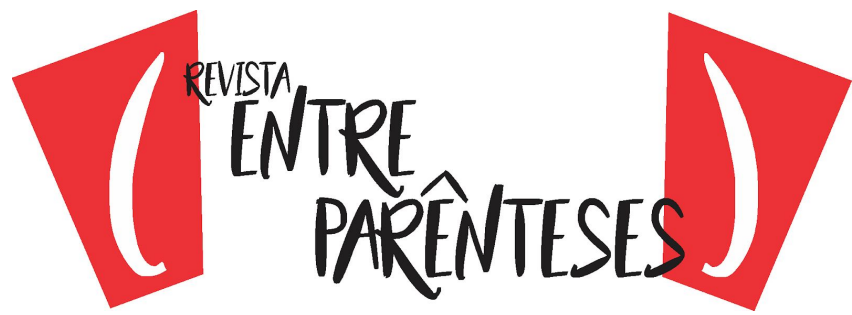

menciona que, "a grande variedade de recursos disponíveis na Amazônia provocava excessivos louvores dos visitantes" (WEINSTEIN, 1993, p. 29).

A imagem de lugar próspero motivou muitas pessoas a deixarem a terra natal e migrarem para esse lugar, como no período do ciclo da borracha. Os diferentes povos que dirigiram-se à Amazônia nesse período estavam fascinados pelo desejo de adquirir grandes riquezas em decorrência do comércio do látex, visto que, "os preços em alta da borracha no mercado internacional atraíram uma corrida à extração do ouro negro" (LIMA, 2009, p. 29).

Após o declínio da comercialização desse produto extrativista efetivaram-se com mais determinação as ações governamentais para a colonização das extensas áreas rurais. Essa atitude do governo levou muitos a enxergarem esse lugar como propício à agricultura, a exemplo dos japoneses. Sobre isso, Cinzas do norte retrata o personagem Oyama, que: "Viera com a família em 1934" (HATOUM, 2005, p. 70). A obra ainda acrescenta que:

Mais tarde chegaram dezenas de jovens agrônomos de Tóquio, passaram uns dias na Vila Amazônia e viajaram para o rio Andirá, onde fundaram uma colônia. Tinham construído um pequeno hospital, uma escola agrícola e Okayama Ken: uma vila onde até hoje moravam os trabalhadores mais antigos. (HATOUM, 2005, p. 70).

A narrativa mostra que a vinda desses orientais para a Amazônia ampliou o seu aspecto plural, já que cresceu a somatória da mistura de raças. "Tiveram filhos com mulheres daqui: jovens mestiços, metade índios, metade orientais, trabalhadores e forçudos" (HATOUM, 2005, p. 70).

A miscigenação também é evidenciada no trecho que segue: "Uma família antiga, americanos que fugiram da Guerra de Secessão e se fixaram no Pará. Os herdeiros venderam o seringal para uma família inglesa, e hoje todos são brasileiros, caboclos com sobrenome inglês" (HATOUM, 2005, p. 77).

Assim, a narração realça o aspecto mestiço desse espaço. Isso é importante, pois, de certa forma, tal focalização firma os amazônidas como sujeitos. 


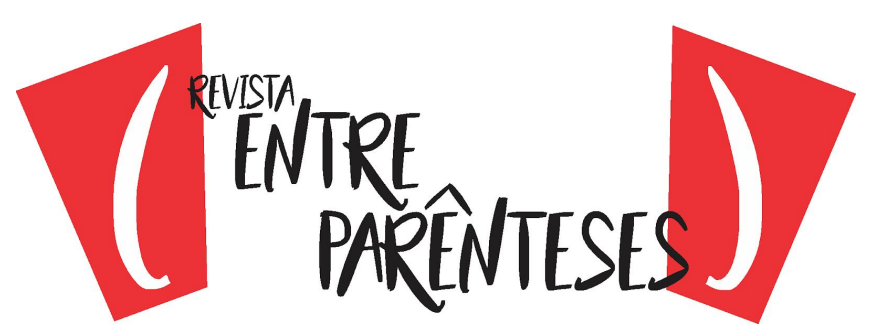

É por isso que Martin-Barbero, menciona "o reconhecimento de uma mestiçagem que, na América Latina, não remete a algo que passou, e sim àquilo mesmo que nos constitui" (MARTIN-BARBERO, 2006, p. 262).

Diante disso, os fluxos migratórios implicam em interações culturais dos indígenas e caboclos com povos oriundos de outros lugares e, nesses contatos é comum haver simbólicos embates e sincretismos. O colonizador guiado pelo eurocentrismo tenta impor seus preceitos aos povos colonizados, no entanto, a resistência às imposições é manifestada. Said diz que, nesses casos, "sempre há resistências, mesmo que infrutíferas" (SAID, 1995, p, 240).

\section{Os nativos diante da cultura do colonizador}

Na Amazônia, os indígenas foram os que mais sofreram com as ações dos colonizadores em nome do progresso e civilização. Elas impunham a esses povos uma nova realidade na qual eram descartados como sujeitos. Essas etnias eram encaradas como torpes e, sendo assim, deveriam ser ignoradas. Por isso, Martin-Barbero diz, "diante do índio a tendência mais forte é pensá-lo como primitivo e, portanto, como um outro, fora da história" (MARTIN-BARBERO, 2006, p. 268).

$\mathrm{Na}$ narrativa hatouniana é possível notar a situação indígena após a política civilizatória. Nesse processo os nativos "participam como vítimas, de uma ordem econômico-social em que desempenham o duro papel de os mais explorados entre os explorados" (GALEANO, 2015, p. 79). Muitos perderam vínculos com suas tribos e foram viver no meio urbano à margem social, como demonstra a narrativa. "Uma família de índios catando as moedas que jogara, moravam ali, entre o gradil e a fachada da casa em ruínas" (HATOUM, 2005, p. 39). Observa-se, portanto, os povos da floresta fora do seu meio em situações degradantes.

Passamos pela frente da igreja e mais adiante vimos uns vultos atrás do gradil da casa abandonada. Comiam sentados no chão. Choro de criança e vozes incompreensíveis. Mundo tocou no meu braço: se 


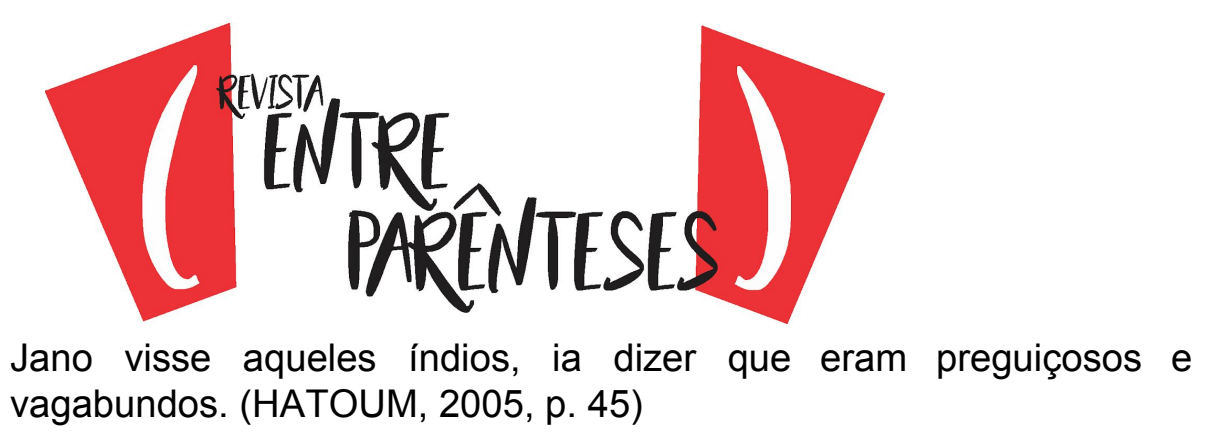

A citação acima realça o aspecto deslocado desses povos no ambiente urbano. É fato que a vida indígena possui relacionamento intenso com a floresta. No espaço de origem, "el tempo individual y social está regulado por el tempo de las aguas, los ciclos del río, el período de la caza, la recoleción, la pesca, la horticultura" (PIZARRO, 2005, p. 133). Assim, essas etnias encontram-se vinculadas à natureza e tal conexão foi fragilizada por meio de ações colonialistas. "Tudo isso é parte de um suposto choque de civilizações, um choque sem fim, implacável, irremediável" (SAID, 2007, p. 13).

A narração mostra uma obra do artista Arana, a qual também evidencia a realidade dos nativos perante os dogmas de civilização e progresso. Nessa produção, o personagem expõe ossos humanos, que segundo ele, são de índios e caboclos, para realizar o trabalho. "Vocês querem saber quais são os temas desse trabalho? Devastação e morte. A floresta queimada é a humanidade morta. [...] Mundo perguntou qual era o título: a dor das tribos. A dor de todas as tribos" (HATOUM, 2005, p. 107, 108).

Em outra criação do artista há uma analogia ao modo de vida indígena após os feitos modernizadores. "Num dos quadros, uma plateia de índios extasiados assistia a uma ópera" (HATOUM, 2005, p. 227). Observa-se nessa citação que índios e forasteiros dividem o mesmo espaço. Isso é a constatação da mudança na cultura dos povos nativos e a presença do múltiplo na Amazônia brasileira.

Contudo, as constantes tentativas dos colonizadores de impor todas as suas práticas aos indígenas não se tornaram efetivas, uma vez que esses povos sempre demonstraram resistência. Embora haja sincretismo, em detrimento de todo o processo de colonização, os índios procuraram manter seus traços culturais. No texto hatouniano, a festa de Parintins é uma demonstração dessa perseverança. Independente da aprovação do colonizador, eles realizam o festival. 


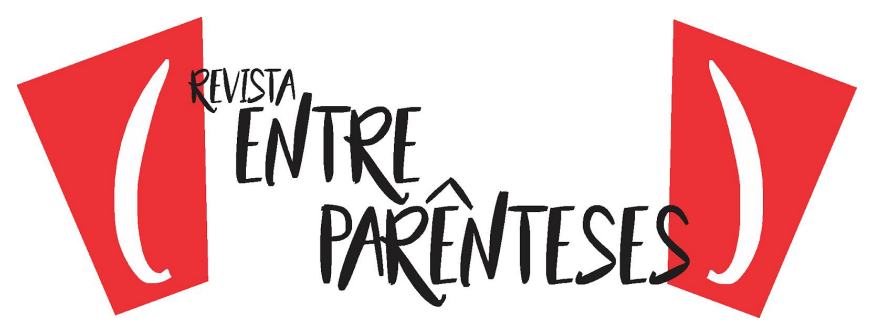

Agora muita gente dançava e cantava em homenagem ao artista morto, um dos fundadores do boi vermelho. As vozes e batuques foram aumentando, o chão trepidava, parecia que a metade da população de Parintins estava ali. Subi num banco para assistir à dança, com seus passos ensaiados ao redor de animais de madeira que se moviam lentamente. (HATOUM, 2005, p. 76)

Outra representação de resistência cultural na narrativa é a arte indígena. As artes continuam sendo produzidas mesmo o colonizador não as reconhecendo. "Na noite da chegada, Mundo me acordou para dizer que havia encontrado um índio velho e doente. Um artista. Acendeu a luz e mostrou uma pintura em casca fina e fibrosa de madeira: cores fortes e o contorno diluído de uma ave agônica". (HATOUM, 2005, p. 69).

Desse modo, a arte é usada como importante ferramenta de luta. Isso é demonstrado em uma obra do índio Nilo, produção que pode revelar o contato das etnias com o colonizador. "Tirou de uma caixa pequenos objetos de madeira que o índio esculpira duas décadas antes: um rosto desfigurado, ou com expressão dilacerante; homens e mulheres jutos, numa expressão de pavor" (HATOUM, 2005, p. 106).

As manifestações artísticas dos indígenas retratam uma forte reafirmação de identidade. Assim, apesar de subjugados pelos colonizadores, eles deixam aflorar uma força para lutar contra as imposições de culturas externas. Por isso, Bhabha diz que, "as forças de autoridade social e da subversão ou subalternidade podem emergir em estratégias de significação deslocadas, até mesmo descentradas" (BHABHA, 1998, p. 206).

Assim, há uma peleja dos povos subjugados pela sua identidade. Mesmo diante das imposições colonialistas, a exemplo dos atos em prol do silenciamento, os nativos procuram resistir, reafirmando suas particularidades. Desse modo, as vozes dos subalternos ecoam para preservar sua identificação no espaço sociocultural. 


\section{As diferenças em torno da cultura}

A luta dos povos subalternos para manter suas práticas se dá por meio de batalhas simbólicas, uma vez que imigrantes e população local, ao coabitarem o mesmo lugar, travam disputas no campo cultural. Na verdade, esse espaço, de acordo com Bhabha (BHABHA, 1998, p. 100), é sempre marcado por embates. O romance hatouniano aponta para vários conflitos nesse meio. As contestações entre o personagem Jano (importante empresário de origem portuguesa) e a população local servem para exemplificar isso.

Jano afirma-se como europeu e reconhece como autênticos apenas seus preceitos culturais. Assim, o personagem é dominado pela "ideia de uma identidade europeia superior a todos os povos e culturas não europeus" (SAID, 2007, 34). Tal mentalidade leva-o a criticar os costumes da população regional, como é possível notar no trecho em que ele fala a respeito da tradicional festa folclórica que acontece anualmente em Parintins. "Boi-bumbá, uma asneira. Começam a vadiarem nesta época. Em março pedem dinheiro para o festival, e em junho ninguém trabalha mais" (HATOUM, 2005, p. 79).

O pensamento desse personagem também é evidenciado quando ele presencia o sincretismo religioso nos atos dos índios. $O$ empresário não compreende que, "toda matéria cultural é híbrida" (ABDALA JUNIOR, 2002, p. 20). Diante disso, o fato de os nativos não seguirem as práticas do colonizador causa-lhe incômodo ao ponto de duvidar da religiosidade dessas etnias. "Da varanda, assistiu ao ritual dos mortos, meio indígena meio cristão [...] São como crianças, um dia rezam para Nossa Senhora do Carmo, outro dia esquecem a santa e a Igreja. A fé dessa gente não está em lugar nenhum". (HATOUM, 2005, p. 73).

Jano crê na hierarquia cultural e nesse pensamento, "o referente de valor para esta jerarquia será siempre eurocentrado" (SEGATO, 2014, p. 24). A compreensão do personagem em torno da cultura leva-o a classificar pejorativamente a população nativa. "Antes esses índios eram tratados por 


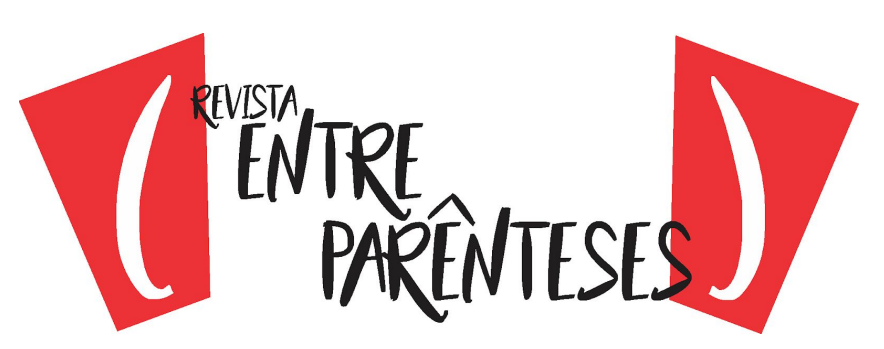

curandeiros, vigaristas do corpo e da alma. Nós pagamos o doutor Kazuma, mesmo assim continuam brutos e ingratos. Esquecem nossos esforços, nossa dedicação." (HATOUM, 2005, p. 73).

É evidente que o anseio de Jano consiste em apagar a cultura local. Esse sempre foi o desejo do colonizador sobre o colonizado, o de "sabotagem dos valores culturais e sociais" (SANTIAGO, 2000, p. 15). Na narrativa, o pai desse personagem também apresenta tal pensamento.

Perguntei por que havia tantas pinturas de São Francisco Xavier, feitas pelo um mesmo artista português. Ele me explicou que, no fim da Segunda Guerra, seu pai mandara trazer aquelas imagens para decorar as casinhas dos empregados japoneses. Queria que todos adorassem o santo, mas eles não gostaram da ideia e as devolveram. (HATOUM, 2005, p. 68).

O desejo hegemônico sobre o outro encontra-se ligado ao pensamento nacionalista. Nessa ideia de nação, as experiências coletivas devem ser tomadas como unitárias. Sobre essa concepção, Bhabha menciona, "de muitos um [...] essa máxima fundadora da sociedade política da nação moderna, sua expressão espacial de um povo unitário" (BHABHA, 1998, p. 203).

No romance, a casa da Vila Amazônia revela esse conceito nacionalista em Jano. Há no personagem o sentimento latente de se reafirmar ao patriotismo lusitano. A ideia de pertencimento pode ser percebida em alguns trechos da obra, como na descrição da piscina da Vila Amazônia, propriedade de Jano.

Azulejos verdes e vermelhos que desenhavam um mapa de Portugal no fundo da piscina, em cujas paredes estavam gravados nomes de cidades, de reis e rainhas desse mesmo país. 'Meu pai dizia que essa decoração era para que se mergulhasse na sua própria pátria', disse Jano (HATOUM, 2005, p. 68).

Outros momentos da obra que também revela a percepção nacionalista em Jano, são os trechos que mencionam a sua constante desaprovação da amizade do filho com os caboclos. O personagem nunca quis a proximidade de Mundo com 


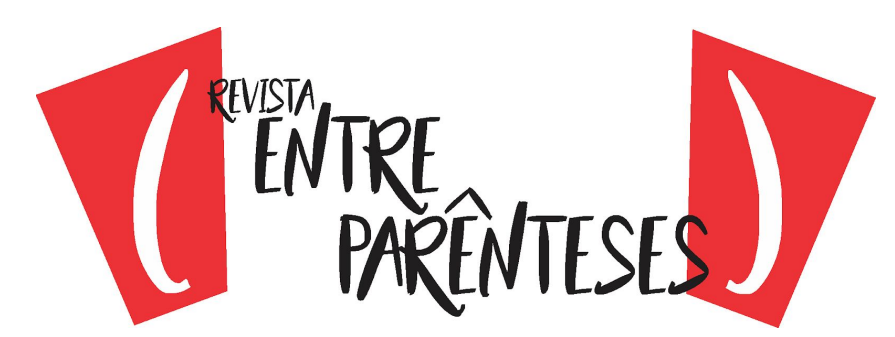

os povos nativos porque desaprovava as práticas dessas pessoas. Isso pode ser percebido nas cartas de Ranulfo.

Quando criança vivia metido nas casinhas de Okayama Ken; queria brincar com a criançada pobre. Jano arrastava o menino para casa. [...] Mundo só se dá com caboquinhos, teu pai dizia a Alícia. As crianças da vizinhança são filhos de casais distintos, mas ele só procura os selvagens. (HATOUM, 2005, p. 124; 151)

Nessa atitude do empresário de origem lusitana está cristalizado o "nacionalismo agressivo, orientado pela ideia de raça" (SAID, 2007, p. 446). Essas ideias polarizam o campo social e cultural, comprometendo a abertura ao pluralismo. É por isso que Martin-Barbero diz que, "a visão homogênea e centralizadora da nação resultaram incompatíveis com a ascensão da pluralidade étnica e cultural" (MARTIN-BARBERO, 2006, p. 267).

Essa forte afirmação nacionalista impossibilita que reconheçamos outras práticas culturais. Assim, inviabiliza a abertura para as diferenças. Martin-Barbero comenta que é o "etnocentrismo que nos impede de perceber o sentido do desenvolvimento daquelas culturas" (MARTIN-BARBERO, 2006, p. 266).

Em virtude do pensamento unitário é que Jano vê os amazônidas como bárbaros. "Dava muito trabalho plantar a civilização na Amazônia. Antes, todo mundo comia com as mãos e fazia as necessidades em qualquer lugar" (HAOTUM, 2005, p. 70). Essa concepção também é evidenciada em outro momento. "Permitiu que os empregados fossem ao enterro, e sabia que o filho estava por ali, que preferia ficar no meio daquela gente" (HATOUM, 2005, p. 73).

$\mathrm{O}$ ato de menosprezar o outro em virtude de preceitos culturais é a denotação de que, "não se tem podido erradicar a existência de estereótipos que uns fazem dos outros" (ACHUGAR, 2006, p. 82). Além de ser a constatação de que a ideias imperialistas continuam presentes.

\section{Considerações finais}




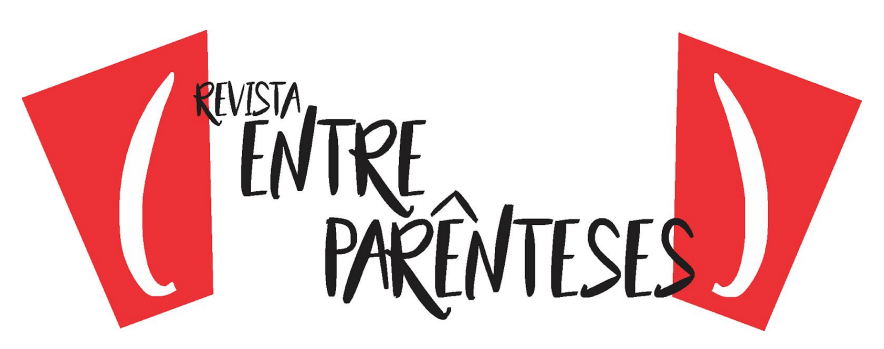

As ações imperialistas comumente foram e são voltadas para a desarticulação das culturas locais porque os conquistadores entendem os povos nativos como inferiores. No entanto, ao longo do tempo, os indígenas e caboclos na região amazônica demonstraram grande resistência ao projeto de dominação, reafirmando suas identidades e preservando suas práticas culturas.

Desse modo, a interação entre colonizador e colonizado são marcadas por embates. Na Amazônia brasileira isso é evidente. De um lado há um projeto colonialista que fez e continua a fazer várias investidas para desmontar a cultura local, do outro se tem os atos indígenas que ganham força para resistir às imposições. Assim, mesmo diante das ações colonialistas voltadas para o silenciamento, as vozes dos indígenas são entoadas.

Diante disso, a narrativa tece uma reflexão em torno da complexidade e a pluralidade no campo cultural na Amazônia brasileira em decorrência das migrações. Assim, Hatoum lê o processo cultural e histórico da região de uma perspectiva múltipla, questionando os estereótipos homogeneizantes, as ideias totalitárias e o pensamento dicotômico, como civilização/barbárie. Repensar essas questões é importante no plano sociocultural porque se pode ter maiores possibilidades de abertura às diferenças. Por isso Achugar conclui que é relevante um "re-delinear de noções como comunidade latino-americana, seu espaço ou seus espaços, seu tempo ou seus tempos" (ACHUGAR, 2006, p. 98, 99).

\section{Referências}

ABDALA JUNIOR, Benjamin. Fronteiras múltiplas, identidades plurais: um ensaio sobre mestiçagem e hibridismo cultural. São Paulo: Editora SENAC, 2002.

ACHUGAR, Hugo. Planetas sem boca: estudos efêmeros sobre arte, literatura e cultura. Trad. Lyslei Nascimento. Belo Horizonte: UFMG, 2006.

BHABHA, Homi K. O local da cultura. Trad. Myriam Ávila, Eliana Lourenço de Lima Reis, Gláucia Renate Gonçalves. Belo Horizonte: Ed. UFMG, 1998. 


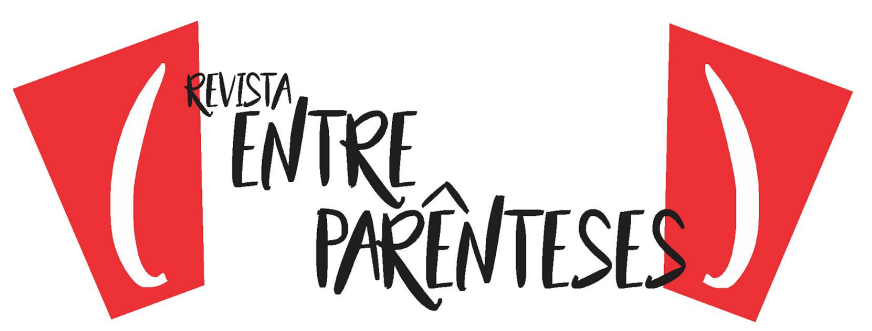

GALEANO, Eduardo. As veias abertas da América Latina. Tradução: Sergio Faraco. Porto Alegre: L e PM POCKET, 2015.

GONÇALVES, Carlos Walter Porto. Amazônia, Amazônias. Segunda edição. São Paulo: Contexto, 2005.

HATOUM, Milton. Cinzas do norte. São Paulo: Companhia das Letras, 2005.

LIMA, Lucilene Gomes. Ficções do ciclo da borracha: A selva, Beiradão e O amante das amazonas. Manaus: Editora da universidade federal do Amazonas, 2009.

MARTÍN-BARBERO, Jesús. Dos meios as mediações: comunicação, cultura e hegemonia. Quarta edição. Rio de Janeiro: Editora UFRJ, 2006.

SAID, W. Eduard. Cultura e imperialismo. Tradução: Denise Bottman. São Paulo: Companhia das Letras, 1995.

Orientalismo: o oriente como invenção do Ocidente. Tradução: Rosaura Eichenberg. São Paulo: Companhia das Letras, 2007.

PIZARRO, Ana. Imaginario y discurso: la Amazonia. In: JOBIM, José Luís [et. al.]. Sentido dos lugares. Rio de Janeiro: ABRALIC, 2005, (pp 130-149).

SANTIAGO, Silviano. O entre-lugar do discurso latino-americano. In: Uma literatura nos trópicos. Rio de Janeiro: Rocco, 2000.

SEGATO, Rita Laura. La perspectiva de la colonialidad del poder. In: QUIJANO, Aníbal Aníbal Quijano - textos de fundação. Buenos Aires: Del Signo, 2014, (pp 13-39).

WEINSTEIN, Barbara. A borracha na Amazônia: Expansão e decadência. Tradução: Lólio Lourenço de Oliveira. São Paulo: HUCITEC, 1993. 